\title{
Adrenomedullin in patients with type 2 diabetes and kidney disease
}

\author{
Emam Waked ${ }^{1}$, Omnia El Bendary ${ }^{2}$, Amna Metwaly ${ }^{3}$, Khaled Younes ${ }^{1}$, \\ Heba Sayed Assal ${ }^{1}$ and Hanan Ali Sayed ${ }^{4}$
}

Nephrology ${ }^{1}$, Clinical Chemistry ${ }^{2}$, Intensive Care Unit ${ }^{3}$, and Public Health ${ }^{4}$ Departments, Theodor Bilharz Research Institute and the Department of Internal Medicine, National Research Center ${ }^{1}$, Egypt

\begin{abstract}
Secreting vasoactive factors such as adrenomedullin (AM) has been intensively investigated due to its vascular protective properties and promising potential as a therapeutic target. The relationship between adrenomedullin and type (2) diabetes needs to be elucidated as it is associated with significant elevation in plasma adrenomedullin levels. The aim of this study was to evaluate the role of adrenomedullin in the development of vasculopathy and its significance as a marker denoting renal affection in type 2 diabetic patients.

Materials and Methods: This study was conducted on 60 diabetic patients, 20 without nephropathy, 20 with nephropathy \& 20 with diabetic nephropathy (DN) on haemodialysis as well as 20 age- and sexmatched healthy controls. All were subjected to full history, Echocardiography, lipid profile analysis and plasma adrenomedullin using ELISA method. Results: plasma AM concentration was elevated in all groups of diabetic patients and increment was dependent on the severity of $\mathrm{DN} \quad(\mathrm{P}<0.0001$, $\mathrm{P}<0.0001), \quad \mathrm{P}<0.0001$ respectively). There were positive correlation between adrenomedullin and left ventricular internal dimensions both in diastole $\&$ systole $(\mathrm{P}<0.001, \quad \mathrm{P}<0.005)$ and negative correlation between AM and ejection fraction (EF) $\mathrm{P}<0.0001$. There was positive correlation between

Correspondence and offprint requests to: Dr. Emam Waked, Nephrology Department, Theodor Bilharz Research Institute, Egypt.
\end{abstract}

adrenomedullin and cholesterol, triglycerides and LDL ( $p<0.002, p<0.001$ and $p<0.003$ respectively) and a negative correlation with HDL $(\mathrm{P}<0.004)$.

Conclusion: Adrenomedullin is supposed to play a role in the pathogenesis of diabetic microvasculopathy in renal patients. So it can be used to identify high-risk subjects and modulating its action would have therapeutic potential in the prevention of diabetic nephropathy.

Key words: Adrenomedullin, diabetes, microvasuclopathy, renal failure.

\section{Introduction}

Type 2 diabetes mellitus contributes greatly to morbidity, mortality, and over all health care cost. These outcomes are derived from the high incidence of progressive kidney dysfunction, making diabetic nephropathy the leading cause of end stage renal disease [1]. For a lesser extent from the atherogenic dyslipidemia which typically presents in type 2 diabetic patients [2].

Hemodynamic-mediated vascular injury was identified as one mechanism in the pathogenesis of diabetic nephropathy. Sustained increase in glomerular capillary pressure driven by increase in plasma flow had been observed, especially in early stages of nephropathy. The elevation in glomerular capillary pressure might be damaging to glomerular endothelial, epithelial, and mesangial cells, thereby 
initiating and contributing to the progression of nephropathy. Although numerous mediators of diabetic hyperfiltration had been proposed, the exact mechanism remained unclear [3]. It is therefore tempting to speculate that endothelialderived vasodilatory substances like adrenomedullin could be involved, since plasma midregional proadrenomedullin (MR-proADM) was increasingly elevated from healthy to renalimpaired subjects and well correlated to magnitude of microcirculatory perfusion. Should this be the case, modulating adrenomedullin action would have therapeutic potential in the prevention of diabetic nephropathy [4].

In healthy states, adrenomedullin circulates at low picomolar concentration, which increases significantly in a number of disease states including congestive heart failure, sepsis, essential hypertension, and renal impairment [4]. Animal model research revealed that hyperglycemia increased vascular adrenomedullin expression [5]. Some investigators reported that type 2 diabetes was associated with significant elevation of plasma adrenomedullin [6], whereas others suggested that increment in plasma adrenomedullin was dependant on the severity of diabetic nephropathy [7].

Adrenomedullin is produced by several cardiovascular tissues including the myocardium, vascular endothelium and vascular smooth muscle [8], exerting vasodilator, natriuretic, diuretic, angiogenic, anti-fibrotic and anti-oxidant actions [9]. Although an endocrine and neurocrine function in the physiological regulation of water intake has been identified [10], attention has focused upon autocrine/ paracrine actions of AM within the myocardium, notably during and following ischemia.

Several studies have demonstrated that AM exerts a potent cardio protective action against ischemiareperfusion injury, and reduced left ventricular remodeling and fibrosis [11].

Aim of the work: To evaluate the role of adrenomedullin in the development of vasculopathy and its significance as a marker denoting renal affection in type 2 diabetic patients.

\section{Material and methods}

This study was conducted on 60 patients selected from Nephrology Department of Theodore Bilharz Research Institute (TBRI) and 20 controls categorized into 4 groups:

- Group 1 included 20 healthy age- and sexmatched healthy controls (12 males and 8 females with mean age of $56.05 \pm 6.3$ ) volunteered from the medical and paramedical staff.

- Group 2 included 20 type 2 diabetic patients (12 males and 8 females with mean age 58.05 \pm 7.6 ). The patients were diabetic without nephropathy as evidenced by absence of microalbuminuria in collected urine over $24 \mathrm{hs}$.

- Group 3 included 20 type 2 diabetic patients (10 males and 10 females with mean age 59.15 \pm 6.6 ). The patients were diabetic with nephropathy as evidenced by presence of macroalbuminuria in collected urine over 24 hrs.

- $\quad$ Group 4 included 20 type 2 diabetic patients (11males and 9 females with mean age 55.95 44.5). The patients were diabetic nephropathy with chronic renal failure (CRF) selected from the Hemodialysis Unit and were on regular hemodialysis sessions 3 times weekly, 4 hours each.

Both patients and controls have no history of myocardial infarction, cardiomegaly, heart failure, or any known history of chronic medical illness.

We excluded patients with hematuria, renal insufficiency of unexplained origin, urinary tract infection, and history of rapidly progressive renal failure, glomerulonephritis, and polycystic kidney diseases.

All subjects underwent routine clinical examination and Laboratory Investigations including:

Blood sugar, blood urea, serum creatinine, creatinine clearance, serum cholesterol, triglycerides, (HDL-C), and (LDL-C). The laboratory investigations were done to all subjects after an overnight fasting, (just before initiation of dialysis in HD patients).

A new immunoluminometric assay targeted at midregional proadrenomedullin [MR-proADM] was performed using a novel sandwich immunoassay (B.R.A.H.M.S. Sevadil LIA; B.R.A.H.M.S., AG, Hennigsdorf/Berlin, Germany) [12]. The assay has an analytical detection limit of $0.08 \mathrm{nmol} / \mathrm{l}$, and the interassay $\mathrm{CV}$ is $<20 \%$ for values $>0.12 \mathrm{nmol} / \mathrm{l}$. EDTA, heparin, and citrate plasma samples are stable ( $<20 \%$ loss of analyte) for at least 3 days at room temperature, 14 days at $4^{\circ} \mathrm{C}$, and 1 year at $-20^{\circ} \mathrm{C}$.

12 lead Electrocardiogram ECG and Transthoracic Echocardiography (TTE) were done to all patients and the control group by Toshiba nemio system, using 2.5 MHZ phased array transducer. Each TEE study included M-mode, two dimensional echocardiography, Doppler and color flow mapping. 
All patients gave informed consent and the study was approved by the Institutional Ethical Committee.

\section{Statistical Analysis}

Data were statistically described in terms of mean \pm standard deviation ( \pm SD). Comparison of more than 2 variables was done by ANOVA test. Pearson correlation between various variables was evaluated and significant correlation was presented by graphs. A probability value ( $p$ value) less than 0.05 was considered statistically significant. All statistical calculations were done using computer programs Microsoft Excel version 7(Microsoft Corporation, NY, USA) and SPSS (Statistical Package for the Social Science; SPSS Inc., Chicago, IL, USA), version 16, statistical program.

\section{Results}

The demographic data of patients and controls were listed in table (1).

Table (2) shows the laboratory data of different groups of patients and controls. There was a highly significant increase in total cholesterol, triglycerides and LDL in between the different groups of patients and $(\mathrm{p}<0.0001, \mathrm{p}<0.0001$, $\mathrm{p}<0.0001)$ and there was a highly significant decrease in HDL between the control and all groups of patients $(\mathrm{P}<0.0001, \mathrm{P}<0.0001, \mathrm{P}<0.003)$. There was a highly significant increase in urea and creatinine between the control and all different groups of patients $(\mathrm{P}<0.001, \mathrm{P}<0.0001 \mathrm{P}<0.0001)$.
There was a highly significant decrease in creatinine clearance between the control and all different groups of patients $(\mathrm{P}<0.0001, \mathrm{P}<0.0001$, $\mathrm{P}<0.0001)$. There was a highly significant increase in HA1c between the control and all different groups of patients $(\mathrm{P}<0.001, \mathrm{P}<0.006 \mathrm{P}<0.0001)$. Blood pressure was significantly increased in all patients compared to the control group $(\mathrm{P}<0.001$, $\mathrm{P}<0.001, \mathrm{P}<0.001)$.

Plasma adrenomedullin was significantly increased in all patients compared to the control group $(\mathrm{P}<0.0001, \mathrm{P}<0.0001, \mathrm{P}<0.0001)$.

Echocardiograpgy of patients and control were listed in table (3); There was a significant increase in left ventricular internal dimensions both in diastole and in systole (LVIDd \& LVIDs) between the control and all patients groups. There was a significant decrease in ejection fraction (EF \%) between the control and all patients groups $(\mathrm{P}<0.0001, \mathrm{P}<0.0001, \mathrm{P}<0.005)$. There was also a significant increase in left ventricular mass index (LVMI) between the control and all groups $(\mathrm{P}<0.0001, \mathrm{P}<0.0001, \mathrm{P}<0.0001)$.

Table (4): shows the correlation between adrenomedullin and laboratory parameters, there was positive correlation between adrenomedullin and left ventricular internal dimensions both in diastole \& systole $(\mathrm{P}<0.001, \mathrm{P}<0.005)$ and negative correlation between AM and ejection fraction (EF) $\mathrm{P}<0.0001$. There was positive correlation between adrenomedullin and cholesterol, triglycerides and LDL $(p<0.002, p<0.001$ and $p<0.003$ respectively) and a negative correlation with HDL $(\mathrm{P}<0.004)$.

Table 1. Demographic data among different groups

\begin{tabular}{|c|c|c|c|c|}
\hline & $\begin{array}{l}\text { Group1 } \\
\text { Mean } \pm S D\end{array}$ & $\begin{array}{l}\text { Group } 2 \\
\text { Mean } \pm S D\end{array}$ & $\begin{array}{l}\text { Group3 } \\
\text { Mean } \pm S D\end{array}$ & $\begin{array}{l}\text { Group4 } \\
\text { Mean } \pm S D\end{array}$ \\
\hline \multirow[t]{2}{*}{ Age } & $56.05 \pm$ & $58.05 \pm$ & $59.15 \pm$ & $55.95 \pm$ \\
\hline & 6.3 & 7.6 & 6.6 & 4.5 \\
\hline \multirow[t]{2}{*}{$\operatorname{sex}$} & M $12(60 \%)$ & M $12(60 \%)$ & M $10(50 \%)$ & M $11(55 \%)$ \\
\hline & F $8(40 \%)$ & F $8(40 \%)$ & F $10(50)$ & F $9(45 \%)$ \\
\hline \multirow[t]{2}{*}{ BMI } & $26.59 \pm$ & $30.8 \pm$ & $35.18 \pm$ & $29.14 \pm$ \\
\hline & 3.58 & 3.60 & 3.38 & 3.09 \\
\hline
\end{tabular}


Table 2. Studied Parameters among different groups

\begin{tabular}{|c|c|c|c|c|c|c|c|}
\hline & $\begin{array}{l}\text { Group1 } \\
\text { Mean } \pm S D\end{array}$ & $\begin{array}{l}\text { Group2 } \\
\text { Mean } \pm S D\end{array}$ & $\begin{array}{l}\text { Group3 } \\
\text { Mean } \pm S D\end{array}$ & $\begin{array}{l}\text { Group4 } \\
\text { Mean } \pm S D\end{array}$ & 1 vs. 2 & $2 v s 3$ & $3 v s 4$ \\
\hline $\begin{array}{l}\text { SBP } \\
(\mathrm{mmHg})\end{array}$ & $120.00 \pm 5.68$ & $135.20 \pm 8.48$ & $141.40 \pm 7.0$ & $152.00 \pm 6.92$ & .001 & .001 & .001 \\
\hline $\begin{array}{l}\mathrm{DBP} \\
(\mathrm{mmHg})\end{array}$ & $76.00 \pm 3.50$ & $84.00 \pm 5.20$ & $86.80 \pm 6.44$ & $96.20 \pm 6.96$ & .001 & .001 & .001 \\
\hline $\begin{array}{l}\text { Cholesterol } \\
\mathrm{mg} / \mathrm{dl}\end{array}$ & $130.8 \pm 29.7$ & $182.8 \pm 35.7$ & $220 \pm 16$ & $256 \pm 24$ & .0001 & .0001 & .0001 \\
\hline $\begin{array}{l}\text { Triglycerides } \\
\mathrm{mg} / \mathrm{dl}\end{array}$ & $118.6 \pm 23.9$ & $194.1 \pm 39.5$ & $266.5 \pm 30.3$ & $305.8 \pm 35.7$ & .0001 & .0001 & .012 \\
\hline $\begin{array}{l}\mathrm{HDL} \\
\mathrm{mg} / \mathrm{dl}\end{array}$ & $46.7 \pm 6.5$ & $33.5 \pm 5.7$ & $27 \pm 4.8$ & $20.4 \pm 4.7$ & .0001 & .0001 & .003 \\
\hline $\begin{array}{l}\mathrm{LDL} \\
\mathrm{mg} / \mathrm{dl}\end{array}$ & $70.6 \pm 14.9$ & $\begin{array}{l}113.45 \pm \\
14.2\end{array}$ & $\begin{array}{l}143.6 \pm \\
30.7\end{array}$ & $179.3 \pm 21.88$ & .0001 & .0001 & .0001 \\
\hline $\begin{array}{l}\text { Urea } \\
\mathrm{mg} / \mathrm{dl}\end{array}$ & $22.4 \pm 2.1$ & $25.6 \pm 3.2$ & $90 \pm 24.4$ & $131.7 \pm 25.2$ & .001 & .0001 & .0001 \\
\hline $\begin{array}{l}\mathrm{S} \mathrm{Cr} \\
\mathrm{mg} / \mathrm{dl}\end{array}$ & $1.1 \pm 0.3$ & $1.2 \pm 0.1$ & $2.9 \pm 0.6$ & $7.5 \pm 1.5$ & .048 & .0001 & .0001 \\
\hline $\begin{array}{l}\mathrm{CrCl} \\
\mathrm{ml} / \mathrm{min} / 1.73 \mathrm{~m}^{2}\end{array}$ & $\begin{array}{l}105.7 \pm \\
12.2\end{array}$ & $\begin{array}{l}102.75 \pm \\
8.3\end{array}$ & $57.3 \pm 10.5$ & $2.27 \pm 0.91$ & Ns & .0001 & .0001 \\
\hline $\begin{array}{l}\mathrm{HbA1C} \\
\%\end{array}$ & $5.8 \pm 0.1$ & $6.4 \pm 2.1$ & $9.6 \pm 1.2$ & $8.2 \pm 0.5$ & .0001 & 0.006 & 0.0001 \\
\hline $\begin{array}{l}\mathrm{AM} \\
\mathrm{nmol} / 1\end{array}$ & $1.1 \pm 0.6$ & $8.4 \pm 3.8$ & $10.3 \pm 6.8$ & $33 \pm 39.6$ & .0001 & .0001 & .0001 \\
\hline
\end{tabular}

SBP: systolic blood pressure, DBP: diastolic blood pressure

$\mathrm{BU}$ : blood urea, $\mathrm{SCr}$ : serum creatinine, $\mathrm{Cr} \mathrm{Cl}$ : creatinine clearance

HDL-C: high density lipoprotein cholesterol, LDL-C: low density lipoprotein cholesterol

AM: adrenomedullin

Table 3. Echocardiographic data among different groups

\begin{tabular}{|c|c|c|c|c|c|c|c|}
\hline & $\begin{array}{l}\text { Groupl } \\
\text { Mean } \pm S D\end{array}$ & $\begin{array}{l}\text { Group2 } \\
\text { Mean } \pm S D\end{array}$ & $\begin{array}{l}\text { Group3 } \\
\text { Mean } \pm S D\end{array}$ & $\begin{array}{l}\text { Group4 } \\
\text { Mean } \pm S D\end{array}$ & 1 vs. 2 & $2 v s 3$ & $3 v s 4$ \\
\hline $\begin{array}{l}\text { LVIDd } \\
(\mathrm{mm})\end{array}$ & $4.3 \pm 0.5$ & $4.6 \pm 0.5$ & $5.4 \pm 0.3$ & $5.98 \pm 0.8$ & .045 & .0001 & .039 \\
\hline $\begin{array}{l}\text { LVIDs } \\
(\mathrm{mm})\end{array}$ & $2.9 \pm 0.6$ & $2.98 \pm 0.35$ & $3.6 \pm 0.53$ & $4.0 \pm 07$ & Ns & .0001 & .051 \\
\hline $\mathrm{EF}(\%)$ & $75.9 \pm 3.46$ & $64.8 \pm 4.7$ & $54.2 \pm 5.8$ & $43.8 \pm 13.8$ & .0001 & .0001 & .005 \\
\hline $\begin{array}{l}\text { LVMI } \\
\left(\mathrm{gm} / \mathrm{m}^{2}\right)\end{array}$ & $79.3 \pm 16.1$ & $128.2 \pm 19.5$ & $184.6 \pm 19.6$ & $215.8 \pm 32.6$ & .0001 & .0001 & .0001 \\
\hline
\end{tabular}

LVIDd: left ventricular internal dimension (diastole), LVIDs: left ventricular internal dimension (systole), EF: ejection fraction, LVMI: left ventricular mass index 


\begin{tabular}{lll}
\hline & $r$ & $P$ \\
& & \\
\hline & & \\
Cr & 0.59 & 0.0001 \\
Cr clearance & -0.48 & 0.002 \\
LVIDd & 0.54 & 0.001 \\
LVIDs & 0.44 & 0.005 \\
EF & -0.63 & 0.0001 \\
LVMI & 0.52 & 0.001 \\
Cholesterol & 0.48 & 0.002 \\
Triglycerides & 0.52 & 0.001 \\
LDL & 0.47 & 0.003 \\
HDL & -0.46 & 0.004 \\
\hline
\end{tabular}

\section{Discussion}

In our study it was found that, plasma AM concentration was elevated in all diabetic patients with and without nephropathy and increment in plasma adrenomedullin was dependent on the severity of diabetic nephropathy $(p<0.0001$, $\mathrm{p}<0.001, \mathrm{p}<0.001$ respectively), this was consistent with findings of others [11,13 \&14].

We found also a positive correlation between AM and creatinine $(\mathrm{r}=0.59, \mathrm{p}<0.0001)$ and a negative correlation between AM and creatinine clearance $(\mathrm{r}=-0.48 \& \mathrm{P}<0.002)$.

Few studies have investigated the relationship between adrenomedullin and type 1 diabetes [15], however other studies showed that type 2 diabetes was associated with significant elevation in plasma adrenomedullin levels, [16].

Previous elegant studies suggested kidney as an important source of adrenomedullin, [17], whereas pulmonary vascular bed could be the main site of receptor-dependent clearance of circulating adrenomedullin [18]. In contrast, the exact site of clearance for MR-proADM is not known at the moment. Therefore, one possible explanation for the elevated plasma MR-proADM concentration among type 2 diabetes with nephropathy could be reduced MR-proADM clearance [19].

It is known that adrenomedullin could exert a wide range of vascular actions (mostly protective). These include endothelium-dependent and -independent vasodilatation, antioxidative stress, stimulation of endothelial nitric oxide production, antiproliferation of vascular smooth muscle cell, and adventitial fibroblast [19]Taken together, the elevation of plasma MR-proADM concentration in type 2 diabetes (especially in the presence of nephropathy) could be an appropriate physiological response to ongoing vascular injury [20] .

Factors that up regulate adrenomedullin are incompletely understood. In vitro data suggested that hyperglycemia might increase vascular adrenomedullin expression [21]. Other postulated mechanisms included acute hyperinsulinemia, [22], increased oxidative stress (based on in vivo studies) [23], and proatherogenic/inflammatory factors such as angiotensin II and endothelin-1 [24].

Plasma AM levels were increased in patients with renal impairment in proportion to the severity of the disease. AM was related to multiple metabolic factors and basal microcirculatory perfusion. Therefore, adrenomedullin might play a role in the pathogenesis of diabetic vasculopathy [25].

Iemura et al [26] investigated the levels of adrenomedullin AM during the process of preadipocyte differentiation and its role in lipid metabolism and cellular signaling mechanism in differentiated adipocytes. They found that AM and its receptor component were highly expressed in cultured adipocytes and may play a role in lipid metabolism via a different signaling pathway.

Our study revealed that there were a highly significant hyperlipidemia in different groups of patients and controls $(\mathrm{P}<0.0001, \mathrm{P}<0.0001, \mathrm{P}$ $<0.0001)$ and the atherogenesis process is much more aggravated in diabetic uremic patients. These 
findings were in agreement with others, who reported that hyperlipidemia is involved in the progression of diabetic nephropathy through playing a pathological role in progressive glomerular injury [27].

In agreement with the previous findings, Bodlaj et al [28], stated that hyperlipidemia in hemodialysis dependent diabetic patients can mediate the inflammation of vessel walls in levels exceeding those hemodialysis dependent patients without diabetes mellitus.

We found also a positive correlation between adrenomedullin and Cholesterol, trigylecerides and LDL $(\mathrm{r}=0.47 \& \mathrm{P}<0.002, \mathrm{r}=0.52 \& \mathrm{P}<0.001$ and $\mathrm{r}=0.47 \& \mathrm{P}<0.003$ respectively) and negative correlation between AM and HDL $(r=-0.46 \&$ $\mathrm{P}<0.004)$. The relationship between LDL cholesterol and adrenomedullin is poorly understood. Limited in vitro data from endothelial cells in rats suggested that oxidized LDL might stimulate the secretion of adrenomedullin [28], which was in agreement with our result.

Other studies, however, could not document any relationship between plasma adrenomedullin concentrations and the degree of metabolic control or risk factors traditionally associated with endothelial injury (e.g., hypertension and dyslipidemia), [6,29].

Levy et al and Burley et al [30,31] stated that AM exerts $\mathrm{Ca}(2+)$-dependent positive inotropic effects in human atrial and less-pronounced effects in ventricular myocardium. The inotropic effects were related to increased cAMP levels.

In our study we found a significant increase in LVIDd, LVIDs and LVMI with significant reduction in EF in group 4 when compared with group 3 patients and the latter group of patients more than group2, who were in turn more than the control group. This means that the worse the degree of the renal insult due to diabetes, the more increase in LV dimensions and LVMI. This result may be due to hyperglycemia with or without insulin resistance, especially in the presence of diabetic nephropathy. Our findings was in agreement with others [32], who stated that the increased arterial stiffness can contribute to increase in LVM by elevating cardiac after load, where the increase in LVM could be viewed as an adaptive response to keep left ventricular wall stress constant and preserve left ventricular systolic function. Henry et al [33] attributed also these findings to other factors such as increased oxidative stress, presence of chronic low grade inflammation and the presence of autonomic neuropathy.

In our study adrenomedullin was positively correlated with LVIDd, LVIDs \& LVMI, ( $r=0.54$ \& $\mathrm{P}<0.001, \mathrm{r}=0.44 \& \mathrm{P}<0.005$ and $\mathrm{r}=0.52 \& \mathrm{P}<0.001$ respectively) and negatively correlated with $\mathrm{EF}$ ( $\mathrm{r}=-$ $0.63 \& \mathrm{P}<0.001$ ).

Several studies have demonstrated that AM exerts a potent cardio protective action against ischemiareperfusion injury, and reduced left ventricular remodeling and fibrosis [9], while others found that mesenchymal stem cells transplantation can inhibit function of cardiac fibroblasts by secreting antifibrotic factors such as AM, resulting in decrease myocardial fibrosis [34].

Plasma MR-proADM levels increase in association with cardiac dysfunction, systemic inflammatory status and systemic blood volume in haemodialysis patients with concomitant cardiovascular disease [16]. These finding were in agreements with our findings.

In conclusion, our study revealed that plasma AM concentration was elevated among subjects with type 2 diabetes, which was further accentuated when nephropathy set in. AM was related to multiple metabolic factors and basal microcirculatory perfusion. Therefore, adrenomedullin might play a role in the pathogenesis of diabetic vasculopathy. Modulating adrenomedullin action would have therapeutic potential in the prevention of diabetic nephropathy.

DISCLOSURE OF CONFLICT OF INTEREST: ALL AUTHORS HAVE NO CONFLICT OF INTEREST.

\section{References}

1. Vallon V, Blantz R, and Thomson S.: Glomerular hyperfilteration and the salt paradox in earely type 1 diabetes mellitus: a tubulocentric view. J Am Soc Nephrol 2003; 14: 530-537.

2. Tenenbaum A, Fisman E, Motro M, and Adler Y.: Atherogenic dyslipidemia in metabolic syndrome and type 2 diabetes: therapeutic options beyond statins. Cardiovascular Diabetology 2006: 5- 20.

3. O'Donnell MP, Kasiske BL, Keane WF.: Glomerular hemodynamic and structural alterations in experimental diabetes mellitus. FASEB J 1998; 2:2339-2347.

4. Julian M, Cacho M, Garcia MA et al.: Adrenomedullin: a new target for the design of small molecule modulators with promising pharmacological activities. Eur J Med Chem 2005; 40:737-750.

5. Cao YN, Kitamura K, Kato J, Kuwasako K, Ito K, Onitsuka H.: Chronic salt loading upregulates expression of adrenomedullin and its receptors in adrenal glands and kidneys of the rat. Hypertension 2003; 42:369-372.

6. Turk HM, Buyukberber S, Sevinc A et al.: Relationship between plasma adrenomedullin levels and metabolic control, risk factors, and diabetic microangiopathy in patients with type 2 diabetes. Diabetes Care 2000; 23:864-867.

7. Nakamura T, Honda K, Ishikawa S, Kitamura K, Eto T and Saito T.: Plasma adrenomedullin levels in patients 
with non-insulin dependent diabetes mellitus: close relationships with diabetic complications. Endocr J 1998; 45:241-246.

8. Widlansky ME, Gokce N, Keaney JF, Vita JA.: The clinical implications of endothelial dysfunction. J Am Coll Cardiol 2003; 42:1149-60.

9. Okumura H, Nagaya N, Kangawa K.: Adrenomedullin infusion during ischemia/reperfusion attenuates left ventricular remodeling and myocardial fibrosis in rats. Hypertens Res 2003; 26:99-104.

10. Beltowski J, Jamroz A.: Adrenomedullin-what do we know 10 years since its discovery? Pol J Pharmacol 2004; 56:5-27

11. Charles CJ, Rademaker MT, Richards AM, Cooper GJ, Coy DH, Nicholls MG.: Hemodynamic, hormonal, and renal effects of intracerebroventricular adrenomedullin in conscious sheep. Endocrinology 1998; 139:1746-1751

12. 12- Morgenthaler NG, Struck J, Alonso C, Bergmann A.: Measurement of midregional proadrenomedullin in plasma with an immunoluminometric assay. Clin Chem 2005; 51:1823-1829.

13. Kinoshita H, Fujimoto S, Tokura T, Hisanaga S, Kitamura $\mathrm{K}$, Eto T.: Plasma mature form of adrenomedullin in diabetic nephropathy. Intern Med 2001; 40:841-2.

14. Lim SC, Morgenthaler NG, Subram AT et al.: The relationship between adrenomedullin, metabolic factors, and vascular function in individuals with type 2 diabetes. Diabetes Care 2007; 30:1513-9.

15. Garcia-Unzueta MT, Montalban C, Pesquera C, Berrazueta JR, Amado JA.: Plasma adrenomedullin levels in type 1 diabetes: relationship with clinical parameters. Diabetes Care 1998; 21:999-1003.

16. Yoshihara F, Ernst A, Morgenthaler NG et al. Midregional proadrenomedullin reflects cardiac dysfunction in hemodialysis patients with cardiovascular disease. Nephrol Dial Tranplant 2007; 22:2263-8.

17. Eto T, Kitamura K, Kato J.: Biological and clinical roles of adrenomedullin in circulation control and cardiovascular diseases. Clin Exp Pharmacol Physiol 1999; 26:371-380.

18. Nishikimi T, Kitamura K, Saito Yet al.: Clinical studies on the sites of production and clearance of circulating adrenomedullin in human subjects.Hypertesion1994; 24:600-604

19. Kato J, Tsuruda T, Kita T, Kitamura K, Eto T.: Adrenomedullin: a protective factor for blood vessels. Arterioscler Thromb Vasc Biol 2005; 25:2480-2487.

20. Ishimitsu T, Nishikimi T, Saito Y et al.: Plasma levels of adrenomedullin, a newly identified hypotensive peptide, in patients with hypertension and renal failure. J Clin Invest 1994; 94:2158-2161.

21. Hayashi M, Shimosawa T, Fujita T.: Hyperglycemia increases vascular adrenomedullin expression. Biochem Biophys Res Commun 1999; 258:453-456.

22. Katsuki A, Sumida Y, Gabazza EC et al.: Acute hyperinsulinemia is associated with increased circulating levels of adrenomedullin in patients with type 2 diabetes mellitus. Eur J Endocrinol 2002; 14:71-75.

23. Katsuki A, Sumida Y, Urakawa $\mathrm{H}$ et al.: Increased oxidative stress is associated with elevated plasma levels of adrenomedullin in hypertensive patients with type 2 diabetes. Diabetes Care 2003; 26:1642-1643.

24. Sugo S, Minamino N, Shoji H, Kangawa K, Matsuo H.: Effects of vasoactive substances and cAMP related compounds on adrenomedullin production in cultured vascular smooth muscle cells. FEBS 1995; 369:311-314.

25. Sjoholm A, Nystrom T.: Endothelial inflammation in insulin resistance. Lancet 2005; 365:610-615.

26. Iemura-Inaba $\mathrm{C}$, Toshio Nishikimi $\mathrm{T}$, Akimoto $\mathrm{K}$, Yoshihara F, Minamino N and Matsuoka H.: Role of adrenomedullin system in lipid metabolism and its signaling mechanism in cultured adipocytes Am J Physiol Regul Integr Comp 2008; 295: 1376-1384.

27. Prichard S.: Impact of dyslipidemia in end stage renal disease. Am Soc Nephrol 2003; 14: 315- 320.

28. Bodlaj G, Berg J, Pichler R, Sailer T, and Biesenbach G.: Type 2 diabetes in patients with end stage renal disease is not associated with further increased serum inflammatory parameters. J. Nephrol 2004; 17: 112-117.

29. Kinoshita H, Kato $K$, Kuroki $M$ et al.: Plasma adrenomedullin levels in patients with diabetes. Diabetes Care 2000; 23:253-254

30. Levy D, Hwang SJ, Kayalar A et al.: Association of plasma natriuretic peptide, adrenomedullin and homocysteine levels with alterations in arterial stiffness: the Framingham Heart Study. Circulation 2007; 115:30785.

31. Burley DS, Hamid SA and Baxter G F.: Cardioprotective actions of peptide hormones in myocardial ischemia. Heart fails Rev 2007; 12:279-91.

32. Lakatta E. and Levy D.: Arterial and cardiac aging: major shareholders in 9 cardiovascular disease enterprises. Part II: the aging heart in health: links to heart disease. Circulation 2003; 107: 346- 354.

33. Henry R, Otto K, Kostense P et al.: Left ventricular mass increases with deteriorating glucose tolerance, especially in women: Independence of increased arterial stiffness or decreased flow mediated dilation. Diabetes Care 2004; 27 : 522- 529.

34. Li L, Zhang S, Zhang Y, Yu B, Guan Z.: Paracrine actions mediate the antifibrotic effect of transplanted mesenchymal stem cells in a rat model of global heart failure. Mol Biol Rep 2008; 27: 1355-1363. 